\title{
Improving forehand performance through functional core training
}

\author{
Cyril Genevois (FRA) \\ ITF Coaching and Sport Science Review 2015; 66 (23): 25 - 28
}

ABSTRACT

This article highlights the importance of functional core strengthening to improve forehand performance. It suggests on-court physical training exercises aimed at improving core rotation power and vertical stability of the body.

\author{
Key words: physical training, \\ forehand, performance \\ Received: 10 April 2015 \\ Accepted: 15 Juy 2015 \\ Corresponding author: \\ Cyril Genevois \\ Email: cyril.genevois@aol.fr
}

\section{INTRODUCTION}

The contribution of sport science, and particularly biomechanics, has made it possible to move from a descriptive analysis (i.e. consequences) to a functional analysis (i.e. causes) of tennis technique. Thanks to a synthesis of the kinematic, kinetic and electromyographic analyses, it has been possible to gain a better understanding of the determinants of post-impact ball speed in the forehand drive (Genevois et al., 2015). Among those determinants, core rotation speed and core stability play an important role. The aim of this article is to suggest the use of some functional training exercises to improve these two factors.

DETERMINANTS OF MAXIMUM RACKET SPEED AT IMPACT Biomechanical studies have been conducted to analyse the contributions of individual segment rotations to maximum racket head speed at impact in the forehand drive. Based on this maximum speed (i.e., 100\%), maximum angular velocities of the various segments studied were expressed as a percentage of maximum speed (Figure 1).

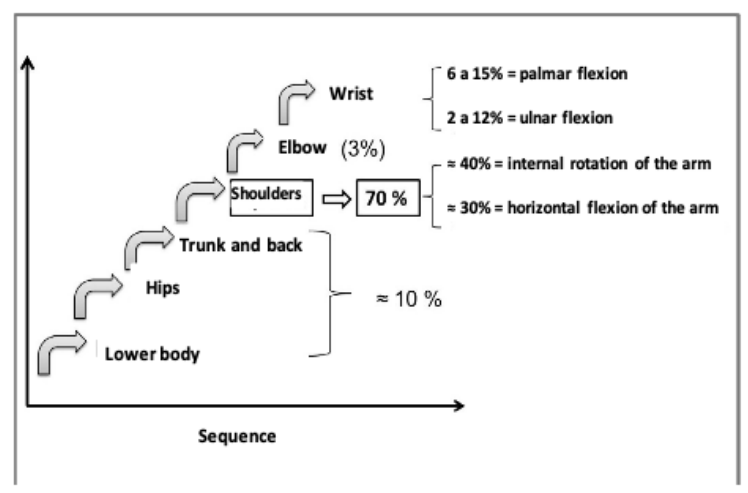

Figure 1. Contributions of individual segment rotations to maximum racket head speed at impact in the forehand (adapted from Elliot et al., 1997).

Although approximately $90 \%$ of maximum racket head speed at impact in the forehand comes from the individual anatomical rotations of the arm, it is important to weigh this value against the results of other studies that show that:
- Upper body rotation is strongly correlated to racket speed, regardless of the position type used or level of play (Bahamonde \& Knudson, 1998).

-Angular velocities of the shoulders (trunk) at impact are discriminants of ball speed after impact and level of play (Landlinger et al., 2010b).

- Ball speed after impact increases as shoulder angular velocities increase, while internal rotation of the upper arm remains constant (Seeley et al., 2011).

- Forced expiration during the acceleration phase resulting in increased core stiffness can improve ball speed after impact (O'Connell et al., 2014).

Consequently, core rotation can be considered as an accelerator of forehand speed. It provides strength while also providing proximal stability for distal mobility (Kibler et al., 2006). Because of the large forces that are applied over a short period of time during the acceleration phase $(<300 \mathrm{~ms})$, development of explosive power is essential.

\section{PRACTICAL IMPLICATIONS}

Improving the function of the core during a forehand stroke implies the necessity to develop its ability to generate power during rotation while providing vertical stability to the body.

\section{Developing maximum core rotation power}

A study using an accelerometer was conducted to assess the maximum power generated during a two-handed side medicine-ball (MB) throw with a rotation movement to the left in a right-handed subject (Genevois, 2013). Results showed that it was positively correlated with maximum ball speed after impact in the forehand and that it was achieved when using a MB mass of $5.7 \%$ of the body weight. From a practical point of view, the knowledge of this fact allows the coach to choose the MB mass according to the desired goal (Figure 2). 


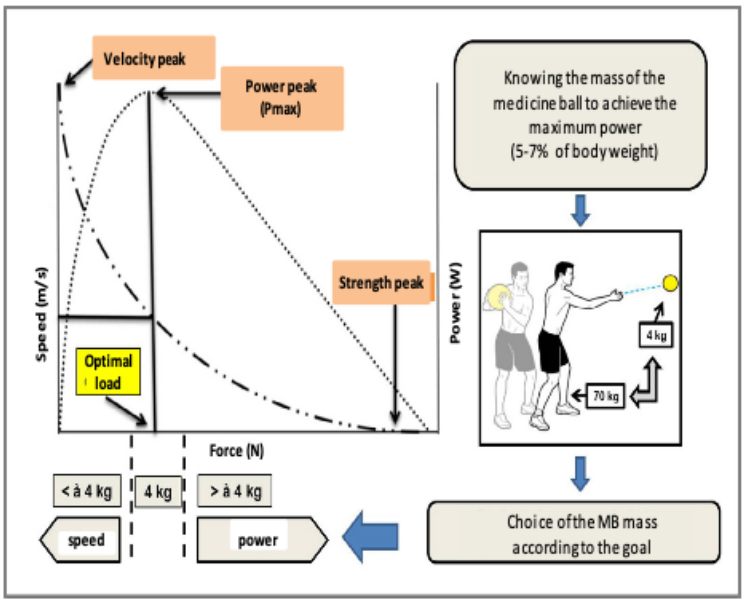

Figure 2. Example of how to adapt MB mass to develop different parts of the strength-speed curve.

A variety of $M B$ masses should be used to ensure complete coverage of the strength/speed curve, progressing from heavier to lighter loads while adapting the number of repetitions per series (Table 1 ).

\begin{tabular}{|c|c|c|c|}
\hline \multicolumn{2}{|c|}{ Strength $\begin{array}{c}\text { Maximum } \\
\text { Power }\end{array}$} & Speed \\
\hline $\begin{array}{c}\text { MB Mass } \\
\text { (\% of body weight) }\end{array}$ & $6-8 \%$ & $5-6 \%$ & $3-5 \%$ \\
\hline $\begin{array}{c}\text { Series } \times \text { Repititions } \\
\text { (for 1 exercise) }\end{array}$ & $2 \times 6$ & $2 \times 8$ & $2 \times 10$ \\
\hline
\end{tabular}

Table 1. Variation of medicine-ball mass and number of repetitions according to targeted goal (adapted from Szymanski et al., 2007).

\section{Developing vertical stability}

In order for the power generated during core rotation to be transferred efficiently, stiffness of the vertical axis around which rotational movements occur is essential. The "antirotation" exercises in standing position, performed in the transverse plane, create long levers and high torques at the spine which are countered through ground reaction forces at the feet. All of the joints between the arms and the feet are called into action in order to stabilize the body. Variations of the basic exercise (Figure 3) can be performed to focus either on front leg stability (Figure 4), as during a square stance position, or on back leg stability (Figure 5), as during an open stance position. This is achieved by adding a stabilization stress in the sagittal plane (forward/backward imbalance). Exercises are performed using alternate tension and relaxation phases in series of 10-15 repetitions. Tension times can then be increased from 2 to 5 seconds by adjusting the number of repetitions.

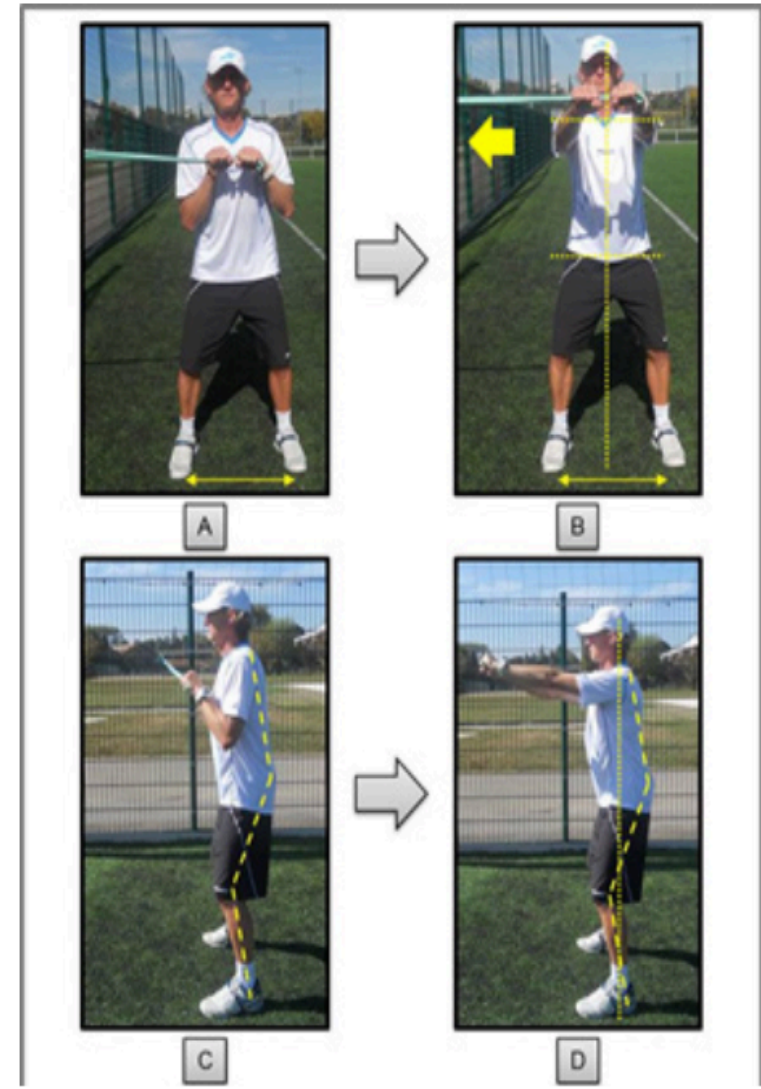

Figure 3. Front $(A / B)$ and side $(C / D)$ views of a stability exercise in the transverse plane. Starting in an athletic stance, the player extends the arms out in front at shoulder height and maintains the position by applying resistance to the elastic band tension which tends to make him rotate. 


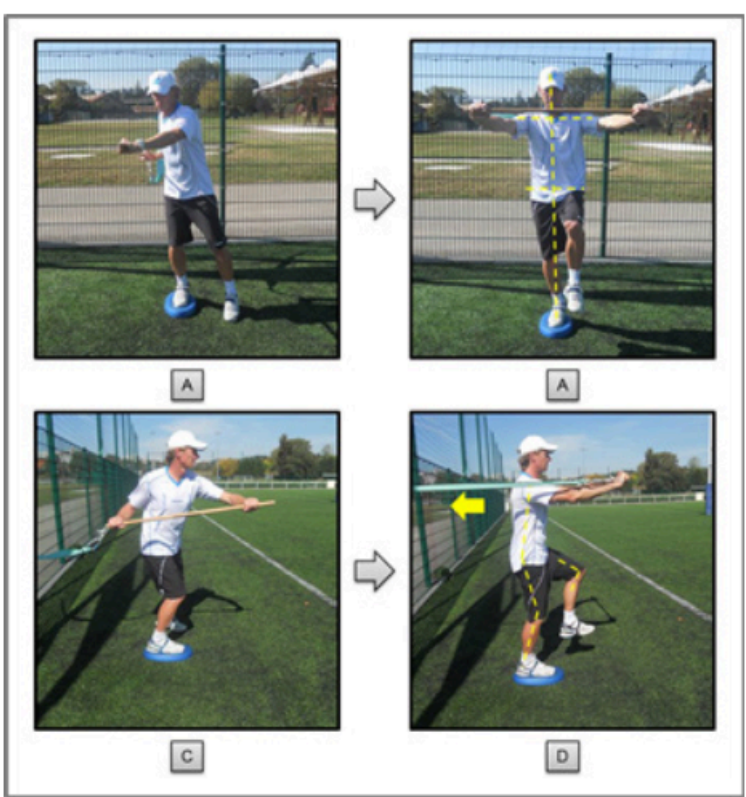

Figure 4. Front $(A / B)$ and side $(C / D)$ views of a stability exercise on the back leg in the transverse and sagittal planes with an unstable base. Starting in a single leg athletic stance, the player extends the arms out in front at shoulder height and maintains the position by applying resistance to the elastic band tension which tends to make him rotate and fall backwards. The left hip and knee flexion ensures body balance as during an open stance stroke.

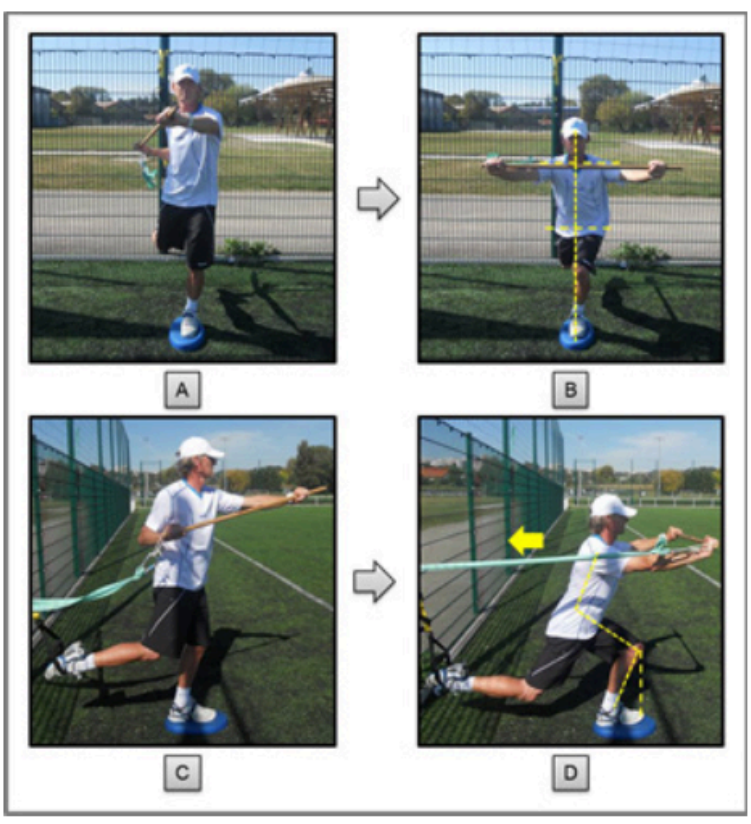

Figure 5. Front $(A / B)$ and side $(C / D)$ views of a stability exercise on the front leg in the transverse and sagittal planes with an unstable base. Starting in a single leg athletic stance, the player extends the arms out in front at shoulder height and maintains the position by applying resistance to the elastic band tension which tends to make him rotate and fall backwards. The left hip and knee are bent as during a square stance stroke.

CONCLUSION

The power generated during core rotation and the vertical stability of the body during the acceleration phase are two key factors of forehand performance. The exercises in this article are designed to achieve this dual goal and can be performed easily on a tennis court without much equipment.

\section{REFERENCES}

Bahamonde, R.E. and Knudson, D. (1998). Kinematic analysis of the open and square stance tennis forehand. Journal of Science and Medicine in Sport, 30, 529.https://doi.org/10.1097/00005768199805001-00165

Elliott, B., Kotara, T. and Noffal, G. (1997). The influence of grip position on upper limb contribution to racket head velocity in a tennis forehand. Journal of Applied Biomechanics, 13, 182-

196.https://doi.org/10.1123/jab.13.2.182

Genevois, C. (2013). Effects of training on forehand drive performance and upper limb overuse in tennis. Doctoral thesis, University of Lyon 1.

Genevois, C., Reid, M., Crespo, M. (2015). Tennis forehand: performance factors. ITF Publication.

Kibler, W., Press, J., and Sciascia, A. (2006). The role of core stability in athletic function. Sports Medicine, 36, 189-198.https://doi.org/10.2165/00007256200636030-00001

Landlinger, J., Lindinger, S., Stoggl, T., Wagner, H., and Muller, E. (2010a). Key factors and timing patterns in the tennis forehand of different skill levels. Journal of Sports Science and Medicine, 9, 643651.https://doi.org/10.1080/14763141.2010.5358 41

Landlinger, J., Lindinger, S., Stoggl, T., Wagner, H., and Muller, E. (2010b). Kinematic differences of elite and highperformance tennis players in the cross court and down the line forehand. Sports Biomechanics, 9, 280-

295.https://doi.org/10.1080/14763141.2010.5358 41

Seeley, M.K., Funk, M.D., Denning, W.M., Hager, R.L., and Hopkins, J.T. (2011). Tennis forehand kinematics change as post-impact ball speed is altered. Sports Biomechanics, 10, 41542.https://doi.org/10.1080/14763141.2011.62930 5

Szymanski, D.J., McIntyre, J.S., Szymanski, J.M., Bradford, T.J., Schade, R.L., Madsen, N.H., Pascoe, D.D. (2007). Effect of torso rotational strength on angular hip, angular shoulder, and linear bat velocities of high school baseball players. Journal of Strength and Conditioning Research, 21, 1117-

1125.https://doi.org/10.1519/00124278200711000-00024

RECOMMENDED ITF TENNIS ACADEMY CONTENT (CLICK BELOW)

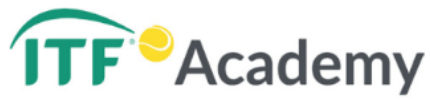

Copyright (c) Cyril Genevois 2015 
This text is under a Creative Commons BY 4.0

\section{license}

You are free to Share - copy and redistribute the material in any medium or format - and Adapt the content - remix, transform, and build upon the material for any purpose, even commercially under the following terms:
Attribution: You must give appropriate credit, provide a link to the license, and indicate if changes were made. You may do so in any reasonable manner, but not in any way that suggests the licensor endorses you or your use.

CC BY 4.0 license terms summary

CC BY 4.0 license terms 